tion or breaking at the edges, and do not form rouleaux, it is evident that anemia is present. ${ }^{9}$ 'The danger signals are still further in evidence when nucleated red cells (normoblasts) appear, and when there is added to these either the giant red cells (megaloblasts) or abnormally small microblasts, the condition is still more serious, since these corpuscles never exist in the normal blood. ${ }^{10}$

Hematology further enables us to differentiate with reasonable precision between chlorosis and pernicious anemia. In the former, though pale in color, the blood coagulates rapidiy, while in the latter coagulation takes place slowly and the red corpuscles do not tend to the formation of rouleaux. The red cells in chlorosis (which are smaller and paler than normal and are frequently deformed) vary from $4,000,000$ to $2,000,000$, rarely falling as low as $1,000,000$, while in pernicious anemia in which the average diameter of the red cells is increased, the count rarely rises above $1,000,000$, and often below this. Cabot gives $1.000,000$ as the average number per cubic millimeter. The white cells are also diminished, varying from 4200 to as low as 500, with lymphocytosis as a prominent feature. Megaloblasts are found in both conditions, but while plentiful in pernicious anemia are rarely noticed in the milder disease, chlorosis. The more megaloblasts in pernicious anemia, the more hopeless the case.

The surgeon would be extremely unfortunate to fail in the recognition of these often obscure lesions, and if possible to correct them before subjecting his patient to the severe ordeal of an operation. In the early recognition of septic processes-chiefly pyogenic-surgery can no longer disregard the value of the blood count, especially the estimation of the leucocytes.

The relative number of leucocytes in a given quantity of blood, or their proportion to the red corpuscles can be readily determined by the use of the Thoma-Zeiss apparatus which, is as weli known, consists of two pipettes, one for the red and one for the white, with a welloutlined and peculiarly constructed slide or counting apparatus, and employed with the ordinary one-sixth laboratory objective. The differentiation by the use of the Daland hematocrit is not considered sufficiently exact to be satisfactory in the hands of the majority of hematologists. It is essential in making these differentiations to bear in mind the normal conditions that at the sea level the average number of red cells per cubic millimeter is 5,000,000 in men, and 4,500,000 in women, and $6,000,000$ in the young and more vigorous adults, while the white cells average about 6500 per cubic millimeter for each sex.

Certain conditions not considered normal. influence the number of leucocytes since in the latter months of pregnancy they are moderately increased, and after parturition, and during the early weeks of lactation, a leucocytosis may be present, without pathological significance. After hemorrhage the leucocyte count is increased, and in diphtheria, erysipelas, trichiniasis, all extensive forms of endometritis and all acute pyogenic processes, leucocytosis exists except in those cases where the vitality of the individual has been overwhelmed by the severity of the septic process, under which condition the leucocytes no longer respond to the demand for the protection of the tissues, and are not present in the

9. The average red corpuscle (normal) is seven micro-millimeters in diameter.

10. A normoblast is a nucleated red cell not over $10 \mathrm{~mm}$. in diam. eter. with a nucleas not more than one-half the diameter of the same. superficial blood in even normal proportions. It is probable that the application of this knowledge is more profitable at present in a study of the various lesions of the abdominal and thoracic organs. We know that in a certain proportion of cases of infection, temperature does not always indicate the increasing gravity of the lesion, while the degree of sepsis can be in great measure determined by the leucocyte count. In impaction of feces, extrauterine pregnancy, floating kidney, gall-stone colic, renal colic, ovarian neuralgia, intussusception, volvulus, internal hernia, twisted pedicle, etc., there is no leucocytosis unless complicated with an acute septic process. In abscess of the liver the leucocyte count ranges from 12,000 to 48,000 , while there is a well-marked increase in all the septic pyogenic processes of the lungs and the pleura.

In osteomyelitis the leucocyte count ranges as a rule from 15,000 to 25,000 , and at times higher. Since in the early stages of this disease it is at times difficult by subjective symptoms to differentiate between rheumatism or gout, the leucocyte count is invaluable in demonstrating at once the pyogenic process.

In that very rare disease, trichiniasis, the leucocytes register sometimes as high as 30,000 , but the special feature is the presence of a large number of eosinophile cells, sometimes as high as 50 per cent.. and in rare cases 67 per cent. of the total number of leucocytes being this form of corpuscle. A very considerable number of cases have been reported within the last year in which the diagnosis had been determined by the presence of eosinophiles.

Not only can the presence of the plasmodium malariæ be recognized in the red blood cells, but hematology is already able to determine between the different varieties of the malarial parasite. It has been shown that the tertian organism takes forty-eight hours to develop and undergo sporulation; the quartan seventy-two, while the estivo-autumnal passes through irregular phases, varying from forty-eight hours to several days.

We are enabled to demonstrate also the presence of the spirochete of relapsing fever discovered by Obermeier in 1873. Although the cork-screw or spiral threads are rarely seen mless the blood is examined in the height of the fever paroxysm, diplococcus-shaped bodies believed to be the spores of this organism are found in the periods of remission.

The time allotted has permitted hardly more than a suggestion of the methods of laboratory research, applicable in the daily routine of surgical practice. To me the moral of the lesson is that the science and art of surgery are inseparable.

\section{THE PROGRESS AND TENDENCY OF HYGIENE AND SANITARY SCIENCE IN THE NINE. TEENTH CENTURY.}

ORATION ON STATE MEDICINE BEFORE THE FIFTY-SECOND ANNUAL MEETING OF THE AMERICAN MEDICAL ASSOCIATION, AT ST. PAUT, MINN., JUNE 4-7. 1901.

GEORGE M. KOBER, M.D.

PROFFSSOR OF HYGIENE, GEORGETOWN UNIVERSITX. WASHINGTON, D. C.

Hygiene is a department of medicine whose object is the preservation and promotion of health and deals, therefore, with all the factors likely to influence our physical welfare. It is not an independent science, but rather the application of the teachings of physiology, 
chemistry, physics, meteorology, pathology, sociology, epidemiology and bacteriology to the maintenance of the health and life of individuals and communities. The subject is very properly divided into personal and public hygiene. In the former the doctrines are applied to individuals, in the latter to communities and states.

This branch of medicine has received such an impetus within the last few decades that many persons regard it of modern origin; such, however, is not the case, for on turning to early history we almost invariably find that the health of the population has been made a subject of legislation. Hygiene was practiced by the Egyptians, the old Indians and Hebrews, and a study of the habits of the primitive peoples shows that a desire to prevent disease is innate to all men.

The Greeks and Romans paid special attention to the physical culture of their youth; they also paid much attention to the water-supply, and Athens was provided with sewers at an early period of her history.

The teachings of Hippocrates, 400 B. C., doubtless bore many fruits, and whether it is true or not, as stated by Galen, that he ordered, during a pestilence at Athens, aromatic fumigation and large fires in the streets, we have at least his writings on air, water, soil, habitations and occupations and his views of local and seasonal influences on sporadic and epidemic diseases. In Homer's "Odyssey" reference is made to Ulysses purifying his house with burning sulphur, and Aristotle, in his "Politica," shows his sanitary acumen when he says: "The greatest influence upon health is exerted by those things which we most freely and frequently require for our existence, and this is especially true of water and air."

The Romans, amidst their military operations, found time to construct the "Cloaca maxima" about 2400 years ago, which not only served for the removal of refuse, but also helped to drain many of the marshes, and constitutes the principal sewer of modern Rome. Aqueducts were made to cover miles upon miles of the surrounding plains, and their splendid ruins, many of which have been restored and are now used for their original purpose, attest the munificence and abundance with which the first of sanitary requisites was supplied to the Eternal City. It is stated that between $400 \mathrm{~B}$. C. and $180 \mathrm{~A}$. D. about 800 public baths were established, among them the "Thermæ Caracallæ," which alone would accommodate 3000 bathers at one time.

During the reign of the Cæsars attempts were made to drain the Pontine Marshes; sanitary officials and physicians to the poor were appointed and homes for poor girls and orphans were established. In the meanirme the true spirit of Christianity asserted itself, and we read of the establishment of hospitals as early as the fourth century; these were speedily followed by infant and orphan asylums and homes for the poor and incurables. During the Middle Ages sanitation received a decided check, ignorant and brutal prejudices appear to have been the ruling spirits and for many reasons it was the most insanitary era in history.

PESTS AND INSANITARY CONDITIONS OF THE MIDDLE AGES.

About this time most of the towns in Europe were built in a compact form, surrounded with walls; the streets were narrow and often winding for defensive purposes, shutting out light and air from the houses. The accumulation of filth was simply frightful. Stables and houses were close neighbors, human filth was thrown on the streets or manure heap. The dead were buried within the churchyards. Sewers and aqueducts having been permitted to fall into disuse, the inhabitants were compelled to resort to wells with polluted subsoil water. All the conditions were favorable for the spread of infectious diseases and in the Fourteenth Century alone the Oriental or bubonic plague, according to Hecker, carried off one-quarter of the population of Europe, or over twenty-five million victims.

Although this disease had been described as early as the third century, B. C., a lamentable state of ignorance is shown, when we remember that the majority of people regarded the plague as the dispensation of God's providence, an evidence of divine wrath, which they hoped to allay by all sorts of self-inflicted punishments, and the passion plays of Oberammergau and elsewhere originated about this time. Others accused the Jews of being the cause, and hundreds were burned at the stake until Pope Urban IV. placed them under his special protection. The Faculty of Paris attributed the epidemic to the conjunction of planets on a certain day in 1345, and the Faculty of Leipzig; with equal gravity, asserted that it was connected with earthquakes, unseen waves of air, inundations, etc. Venice, alone of all Europe took a sensible view of the matter, and for the first time in history, in 1348, appointed three guardians of public health, and the rules adopted later to isolate infected houses and districts for forty days has given rise to the term quarantine-from quaranta giorni.

The repeated invasion of the Oriental pest appears to have everywhere compelled some sanitary efforts and an imperial decree in 1426 required the appointment of city physicians throughout Germany, whose duty it was to adopt preventive measures. A city ordinance of Nürnberg in 1562 gives detailed directions as to the quality of bread, beer and wine offered for sale, the cleaning of streets and houses, the disposition of infected clothing and bedding, the fumigation with sulphur and straw of pest-houses, ete.

In 1685 Prussia established a central medical bureau, and appointments of health officers and privy medical counsellors were made, whose duties consisted in advising the men entrusted with the care of the government on matters relating to public health, and some of these titles are still in vogue in Europe. At the beginning of the eightenth century. Prussia, upon being threatened with an invasion of the bubonic plague from Austria, created the "Collegium Sanitatis," popularly called the "Pest College," which was really the beginning of the present state board of health. In 1762 a sanitary council was established in every Prussian province, for the prevention of disease among man and animals. About the same time sanitary improvement: in the way of widening streets for the purpose of supplying more air and light to the habitations, and better methods for the collection and removal of the wastes of human life were introduced, but, broadly speaking, at the close of the seventeenth century the habits of the people in Europe were generally filthy and in striking contrast to those observed among the most untutored savages of the present day.

In Madrid, we are told by Barcome, in his history of epidemics, "that not even a privy existed in 1760 . It was customary to throw the ordure out of the windows at night, and it was removed by scavengers the next day. An ordinance having been issued by the king that every householder should build a privy, the people violently opposed it as an arbitrary proceeding, and the physicians remonstrated against it, alleging that the filth 
absorbed the unwholesome particles of the air which otherwise would be taken into the human body. His majesty, however, with commendable zeal, persisted. but many of his citizens, in order to keep their food wholesome, erected privies close to their kitchen fireplaces."

With such unsanitary conditions we need scarcely be surprised that the mortality in towns was greater than their birth-rate and that the city population had to be recruited continually from the country. Toward the close of the eighteenth century many sanitary reforms were effected, however, especially in connection with infant and orphan asylums, and the management of schools and prisons. Of special importance is the brilliant discovery, or re-discovery; of vaccination by Jenner in 1796.

PROGRESS OF SANITATION IN THE NINETEENTH CENTURY.

The nineteenth century can boast of many advances in hygiene, particularly since the European invasion of cholera in 1830. The English towns which had been visited by this disease and those fearing similar scourges were willing to profit by their sad experience, and freely instituted sanitary reforms in the establishment of sewers, public water supplies, sanitary homes, etc.

The example of England was followed by all civilized nations, with similar results. The efforts of sanitation, as taught by Dr. Parkes, were demonstrated during the Crimean War and, as beautifuly expressed by Virchow during our Civil War, reached "the highest point in humane efforts ever attained in a great war," and we may proudly add have even been excelled during our late Spanish-American War.

PROGRESS OF SANITATION IN THE UNITED STATES.

While the people of the United States were not slow in adopting and originating sanitary measures of great value, our ideas of personal liberty, guaranteed to us by the Constitution, evidently prevented early legislation in matters of public health, for fear that such legislation might affect the personal habits of the citizen and lessen his freedom of action. Dr. Samuel W. Abbott, in his masterly exposition of "The Past and Present Condition of Public Hygiene and State Medicine in the United States," records, however, the gratifying fact that the early colonists recognized the need of preserving their records, which constitute the foundation stone of public hygiene, by enacting a law in 1639 "that there be records kept of the days of every marriage, birth and death of every person in this jurisdiction."

The importance of vital statistics is not fully appreciated at the present day, and yet, as remarked by Dr. Billings, "when we wish to study the healthfulness of a city, whether it is getting better or worse, or judge correctly the effect of certain sanitary laws, we should not only know the number of deaths, but also the amount and character of the prevalent disease, together with accurate information as to the number of population. at different ages." It is a matter of regret, therefore, that even now only ten states, Connecticut, Delaware, Maine. Massachusetts, Michigan, New Hampshire, New Jersey, New York, Rhode Island and Vermont, have anything like a satisfactory system of vital statistics.

According to Abbott: "Up to the close of the eighteenth century and for several decades of the nineteenth, almost the only health legislation which was enacted in the different states in the Union consisted in a few laws relating to smallpox, since this pestilence was scarcely ever absent for many years at a time from any city or village, 'till after the general introduction of vaccination."

Dr. Waterhouse, of Cambridge, having secured a supply of vaccin lymph from Dr. Jenner, introduced vaccination in Boston in 1800 , and Dr. Seaman in New York in 1801. In the same year President Jefferson received some virus from Dr. Waterhouse and was vaccinated by Dr. Grant, of Georgetown.

The invasion of cholera from Canada in 1832, and the epidemic of 1848-1849 here, as in Europe, aroused public interest in sanitary reforms, and the legislature of Massachusetts in 1849 appointed a commission to make a sanitary survey of the state, and we are told by $\mathrm{Dr}$. Abbott "that this was done none too soon, for in that year the general sanitary condition of the state, as shown by the report of the commission. was deplorable and the death-rate unusually high. Only a few towns had then introduced public water-supplies. Cholera was beginning to appear again and dysentery and other infectious diseases were more destructive than they had been for many years."

\section{HEALTH BOARDS.}

New Orleans having lost 8000 victims of cholera in 1832 , out of a population of about 55,000 , and anxious to maintain a quarantine, secured the enactment of a law in 1855 for the establishment of a state board of health; in 1869 a more comprehensive board was established in Massachusetts, followed in 1870 by California, since which time nearly all of the states and territoriesforty-two in number-have followed the example. Pari passu and in many instances preceding the establishment of state boards of health, sprung into existence our local boards of health, who adopted measures for the control and restriction of infectious diseases, for the abatement of local nuisances, for the sanitary inspection of the food-supply, schools, public buildings and institutions and tenements; street cleaning and removal of refuse, registration of vital statistics, supervision of burials and of municipal water-supply, sewerage, and sewage disposal, care of bathing establishments, regulation of offensive trades, etc.

EFFECTS OF VOLUNTARY ORGANIZATION ON SANITATION.

In September, 1872, the American Public Health Association was organized; in 1873 , the Section on State Medicine of the American Medical Association was created; since then the American Climatological Association, the Sanitary Council of the Mississippi Valley, the American Sanitary Association, and the American Health Resort Association have been organized, and numbering, as they do, among their members some of the best minds in the profession, much good has been accomplished by these bodies, and the so-called "sanitary conventions" in molding public opinion and in framing and recommending health laws. There is no doubt, however, that all these organizations were stimulated into existence by the lofty tenets of our Code of Ethics, ${ }^{1}$ in which the duties of the profession to the public were prescribed as early as $184 \%$.

1. Article 1, paragraph 1, reads: As good Citizens, it is the duty of physicians to be ever vigilant for the welfare of the community and to bear their part in sustaining its institutions and burdens; they should also be ever ready to give counsel to the public in relation to matters especially appertaining to their profession, as on subjects of medical police public hygiene and legal medicine. It is their province to enlighten the public in regard to quarantine regulations, the location, arrangement and dietaries of bospitals, asylums, schools. prisons, and similar institutions in relation to the medical police of towns, similar institutions; in etc. and in regard to measures for the as drainage, ventilation contagious diseases, and when for the prevention of epidemic and contaglous diseases, and when pestilence prevalls it is their duty of the suffering, even at the feopardy of labors for the alle 
Indeed, the American Medical Association, according to Dr. N. S. Davis, Sr., gave prominent attention to State Medicine and sanitation from its first meetings. At the second annual meeting, in 1849, standing committees were appointed on forensic medicine and on hygiene and reported annually on these topics and on meteorology, medical topography and epidemic diseases until 1860, when work in Sections was commenced. Dr. A. N. Bell, of New York, delivered the first address on State Medicine in general session of the Association in 1874, followed in 1875 by Dr. N. I. Bowditch, of Boston. ${ }^{2}$ In this connection, I may say that there is need of reliable information on the geographical distribution of diseases like goiter, cretinism, etc., and county medical societies would contribute much to the common fund of knowledge by placing on record information of this character.

\section{NATIONAL BOARD OF HEALTH.}

The cholera epidemic of 1872 and 1873 resulted in the appointment of a commission by Congress. This, together with the yellow fever epidemic of 1878 in the Southern States, affecting, according to Sternberg, over 74,000 persons, with 16,000 deaths, called attention to the necessity of some central sanitary organization. In March, 1878, Congress created a national board of health, whose duty it was to make investigations into the causes and means of prevention of contagious and infectious diseases, to indicate measures of national importance and to be a center of information for all matters relating to public health. For want of appropriation this important body has ceased to exist, and since 1883 the duties relating to international and interstate quarantine have been discharged by the SurgeonGeneral of the U. S. Marine-Hospital Service; his bureau, apart from the management of hospitals and stations for the care of sick and disabled seamen of the merchant marine, has also undertaken the collection and dissemination of mortality statistics and sanitary information, scientific investigation into the causes of disease, the physical examination of immigrants under the law, excluding those affected with contagious diseaseservice in the office of consuls at foreign ports to assure the accuracy of bills of health-and other miscellaneous duties. Since Congress has failed to act upon the President's repeated recommendation and the petition of numerous medical societies for the creation of a national health establishment, there is no good reason why the scope of duties and powers exercised by the MarineHospital Service should not be enlarged. Indeed, the last Congress appropriated sufficient money for the erection for a laboratory "for the investigation of infectious and contagious diseases and matters pertaining to the public health," which marks the beginning of a new era in national sanitary legislation.

NATIONAL AND INTERNATIONAL QUARANTINE.

The question of an efficient system of national and international quarantine against Asiatic cholera, yellow fever, smallpox, typhoid fever, bubonic plague, leprosy has engaged the attention of sanitarians for years, especially since it become known that these diseases, particularly cholera, are generally carried along the highways of travel and commerce. Special efforts were made after the completion of the Suez canal and other rapid transit facilities, to guard Europe from the inrasion of cholera from India, and since 1892 these efforts have been quite fruitful. At all events with

2. Information kindly furnishod by Drs. N. S. Davis, Sr., and Geo. H. Simmons, letter of April I $8,1901$. efficient quarantine regulations involving inspection of vessels, passengers and crew, the detention of the sick and disinfection of all others, including personal effects, cargo and vessels, and proper notification, we have been enabled to keep these diseases from our shores, and if other nations do the same, they should be restricted to their original home. General Wyman's plan, as outlined in his address before the Pan-American Medical Congress, contemplates an international system of sanitation; while his proposition refers especially to yellow fever in the Western Hemisphere, it is equally applicable to the home of cholera and the oriental plague.

In the light of the recent researches by Reed and Carroll as to the transmission of yellow fever by means of mosquitoes, our views concerning quarantine and disinfection in this disease may have to be modified, but in the meantime the fight against the mosquitoes will go on; whether this will be effectually accomplished by insecticides and screens, or the more rational method of drainage of the soil, remains to be seen; in either event malarial countries will likewise be benefited.

\section{HAS HUMAN SUFFERING BEEN MITIGATED AND HUMAN LIFE GREATLY PROLONGED BY EFFORTS IN SANITATION?}

Our answer is an emphatic "Yes." Professor Finkelnburg, of Bonn, estimates that the average length of human life in the sixteenth century was only between 18 and 20 years; at the close of the eighteenth, it was a little over 30 years, while to-day it is over 40 years; indeed, the span of life since 1880 has been lengthened about six years. as shown by statistics, in Mulhall's "Dictionary of Statistics" (4th edition, London, 1899).

The mortality of Iondon between 1660 and 1678 was 80 per 1000 of inhabitants; from 1728 to 1780,51 per 1000 ; from 1801 to 1835 it was still 29 , while at the present time it averages betwen 17 and 19 per 1000 .

\section{INFLUENCE OF SEWERS AND PUBLIC WATER-SUPPLIES.}

Without underestimating the brilliant achievements of Jenner's discovery of vaccination in 1796 , which as a preventive measure has saved millions of lives, no two factors have contributed so much to the general result as the improvement of the air we breathe and the water we drink. Indeed, we have ample evidence that, with the introduction of sewers and public water-supplies, the general mortality in numerous cities, during the past forty years, has been reduced fully one-half, the good effects being especially shown by a marked decrease in the number of cases of typhoid fever, diarrheal diseases and consumption. The vital statistics of Great Britain furnish the proof. The mortality of Salisbury within the last thirty years has been reduced from 40 to 16 per 1000 ; at Dover, from 28 to 14 per 1000 ; at Rugby, from 24 to 10 per 1000 ; at Croydon, from 28 to 15 per 1000 , and at Matlock, from 18 to 9 per 1000 .

The history of every sewered city shows a lessening of the typhoid death-rate subsequent to the construction of the sewers and that the typhoid rate is always higher in sections supplied with privy pits and box privies, than in the houses connected with sewers. In 1895 the speaker pointed out that typhoid prevailed in the city of Washington and suburbs in 1 of 81 houses with privies, and in only 1 in 149 of those connected with sewers, and the health officer of Nottingham has since then presented similar evidence. The only reasonable explanation for this is that sewers carry away the filth that otherwise would contaminate the soil and ground water, but even if there were no wells, these makeshifts are still a source of danger in so far as they favor the 
transmission of the infection by means of flies, nor can the possibility be ignored that the germs in leaky or overflowing boxes may reach the upper layer of the soil, and, with pulverized dust, gain access to the system. This conclusion, and the agency of flies in carrying the germs from box privies and other receptacles from typhoid stools to the food-supply, was enunciated in my report in 1895 and appears to have found ample support in the experience of the late Spanish-American War.

INFLUENCE OF IMPROVED WATER-SUPPLIES.

According to Dr. Abbott, the number of towns in the United States before 1800 having a public water-supply was only 16 , supplying about 2.8 per cent. of the existing population; in 1850 there were only 83 public water-works, supplying about 10.6 per cent. of the census population; in 1897 the total number was 3196 , supplying about 41.6 per cent. of the population.

A summary of the evidence on this subject reveals the significant fact that cities, both at home and abroad, in which there has been the most marked decrease in typhoid fever death-rate, are those in which a pure supply has been substituted for a pre-existing contaminated one. Thus, for example, the typhoid fever death-rate in Boston in 1846-1849 was still 17.4 per 10,000; in $1890-1892$ it had fallen to 3.2 per 10,000 , the eity having in the meantime expended $\$ 25,000,000$ on its water-supply. The typhoid fever death-rate in Chicago from 1890 to 1892 averaged 12.5 per 10,000 . After improving the water-supply it fell with every step in improvement until last year it was only 1.9 per 10,000 , a total reduction of 84.8 during the decade. The rate from this disease in Lawrence. Mass., for five years prior to 1893 , was 12.7 per 10,000 . After the establishment of sand filters, in September, 1893, the rate fell during the first twelve months to 5.2 per 10,000 .

Munich was notorious for its excessive typhoid fever death-rate, it being 29 per 10,000 in 1856 . With the introduction of a pure water-supply and improved sewer system it has fallen to less than 2 per 10,000 . The experience of London, Berlin, Vienna, Albany and a host of other cities has been precisely the same. ${ }^{3}$

\section{SEWAGE DISPOSAL AND RIVER POLLUTION.}

When we remember that in 1896,41 per cent. of our population lived in towns having public water-supplies, and only 28.7 per cent. in sewered towns, we fear that the municipal authorities have failed to recognize the necessity that a system of public sewerage must go hand in hand with the public water-supply, the neglect of which simply compels recourse to the various makeshifts for the collection and removal of excreta, and leads to soil pollution and all the other evils already referred to.

In view of the fact that self-purification of rivers is a slow and uncertain process, and that streams once polluted with excrementitious matter can not be considered a safe water-supply, it is high time for civilized communities to take steps toward removing the danger to be found in rivers, which are the sewers and at the same time the sources of public water-supplies.

We know, from statistics collected by the MarineHospital Service, that the towns and cities located on the banks of the Ohio, Potomac, Mississippi, Merrimac, Connecticut, Missouri, the Red, the Columbia and 3 . In 25 cities using unfiltered water the average typhoid death-
rate is still 7.7 per 10,000 ; in 5 American cities supplied with water filtered by the American process, the rate is 5 , applied with water 1.1 per 10,000 in cities supplied with water fitered against a rate of or inglish method. The average rate water fitered by the natura with mountain springs or deep wells of: cities in Europe supplied 0.7 per 10,000 .
Wrabash rivers show a marked prevalence of typhoid fever, confirming what has elsewhere been proved, that this disease, as also cholera, dysentery and diarrheal diveases can be carried from one town or city to another by means of water-courses. There were probably no fewer than 35,000 deaths caused by typhoid fever alone throughout the United States last year and, based upon an estimated mortality of 10 per cent., it is within reason to assume a yearly prevalence of 350,000 cases of this disease. The average duration of a case of typhoid fever is not less than thirty days. If we calculate that an average of $\$ 1$ a day is expended for care, treatment and loss of work, and that the value of a human life is $\$ 5000$, we have a total loss in the United States of $\$ 185,500,000$ per annum, from one of the so-called preventable diseases. Reduce the prevalence of this single disease one-half, which has been accomplished in England, and the oft-recurring question: "How is it our fathers got along without these so-called modern improvements?" will be satisfactorily answered from an economic point of view.

One of the most pressing needs is an investigation into the pollution of water-supplies when such pollution affects or threatens to affect the sanitary condition of the people of more than one state, because the individual states are powerless to protect themselves against the misdeeds of their neighbors. Mr. Barthold's bill for the appointment of a river pollution commission was defeated; yet that same Congress appropriated $\$ 40,000$ for the extermination of the gipsy moth. England enjoyed the benefit of such a commission as early as 1855, and, in order to prevent, remedy and remove the danger of polluted water-supplies, adopted a comprehensive system for the disposal of sewage and water filtration, the fruits of which have already been referred to.

No community or individual has a right to pollute streams used for public water-supplies any more than a man has to contaminate his neighbor's well. This principle is very well appreciated by some of the nations in Europe. Thus the inhabitants of a town in Belgium suffered from the effects of a river polluted by the French and the French Government not only compelled the offending town to dispose of its sewage by irrigation, but also granted a subsidy for this purpose.

In the interest of public health it is to be hoped that every state in the Union will take steps toward the prevention of river pollution, except when towns are located close to the sea, and no lower towns are obliged to use the water for drinking purposes.

In 1878 the British Government appointed a committee to inquire into the several methods of sewage disposal and concluded that it can be best and most cheaply disposed of by the process of land irrigation for agricultural purposes, but as this is not always practicable other modes of dealing with sewage have been proposed.

It is a gratifying fact that within the past ten or twelve years over 100 communities in the United States have established plants for the disposal of sewage. The first attempt was made in 1872 at the state insane asylum, Augusta, Me., since which time seventy-eight plants for the disposal by irrigation, and fifteen by chemical treatment have been established and over forty more projected.

\section{PURE FOOD AND DRUG LEGISLATION.}

The first movement toward securing comprehensive legislation against the adulteration of foods and drugs 
in this country was made in 1879 . This is all the more surprising because Dr. Mann, in his "Medical Sketches of 1812," remarks that "the bread on the Niagara was made of damaged flour, such as was either not nutritious or absolutely deleterious." It was believed also that the flour contained in some instances an earthy substance, and that this adulterating substance was plaster-of-paris. Again, during the Civil War, as early as the winter of 1861-62, an extract of coffee furnished the troops in the vicinity of Alexandria produced nausea and vomiting, and subsequently a government contractor, for having practiced food adulteration, was sentenced to a protracted imprisonment.

Instances, therefore, were not wanting pointing to the necessity of such laws; nevertheless, it was not until 1881 that three states, New Jersey, New York and Michigan passed laws to prevent the adulteration of food and drugs. The law in New York commenced in the summer of 1882. At the close of the year 286 samples of food and drugs had been submitted to the public analyst for examination, of which 194 had been reported on. Of 119 samples of food, 50 were found adulterated; while of 75 samples of drugs, 32 were adulterated.

Since 1883 quite a number of states have enacted similar laws, but I regret to say that in spite of the absolute necessity for national legislation. which has been agitated ever since 1892, so far every bill presented to Congress has failed to become a law, and food adulterated in one state can be taken to another and sold. It would lead me entirely too far even to touch upon all the frauds which are daily perpetrated. Some adulterations are harmful, others are not. I will simply refer to a very universal article of food, viz., milk. New York City obtains its milk-supply from five states, and amounted in 1896 to nearly r29,000 quarts a day. Analysis of the milk sold some years ago showed an average dilution with 33 per cent. of water. The state inspector found 12 per cent. water added and 20 per cent. of cream removed, the fraud amounting to over $\$ 10,000$ a day. The results in St. Louis, Chicago, and elsewhere were similar, and indicated the desirability of stringent laws to protect the poca.. of the consumer, but when we remember the frightful infantile mortality, and the fact that the speaker has recently presented his conclusions, based upon 195 epidemics of typhoid fever, 99 of scarlet fever and 36 of diphtheria and that 52 of these outbreaks occurred in this country since 1882 , we see at once that the milk traffic should be under strict sanitary control. ${ }^{4}$

\section{LAWS REGULATING THE SALE OF DRUGS AND POISONS.}

Forty-two states and territories have enacted laws to regulate the sale of poisons, but a careful study shows that they should be amended, and greater restriction placed on the sale of poisons generally. A recent investigation by a committee of the Medical and Surgical Society into the extent of the opium and drug habit in the District of Columbia developed some interesting facts, and led to the conclusion that one class of subjects have developed the opium habit by the use of the milder preparation of opium and some of the various proprietary or secret remedies commonly employed as domestic remedies, such as paregoric, McMunn's elixir, chlorodyne, blackdrop, soothing syrup, diarrhea mixtures, pain-killers, etc. Those of another class have evi-

4. The results achleved by the health officers of every large city, notably by Reynolds, of Chicago, Wende, of Bufialo, and Woodward, of Washington, in the reduction of infantile mortality, amounting in some instances to over 50 per cent., show the advantages of pure food legislation. dently acquired the habit by the constant use of prescriptions containing opium, or its preparations, for the relief of pain, the individuals being at first quite unconscious of the enslaving nature of the drug. Still another class of persons belong to the moral degenerates of fast men and women who have acquired the habit by contact with opium habitues, including opium smokers, and through solicitation, invitation and persuasion have fallen victims to the vice. Since the opium habit is often established by the unauthorized and indiscriminate renewal of prescriptions containing opiates, the New York legislature very wisely enacted, in 1886, a law that no pharmacist shall refill more than once prescriptions containing opium or morphine, or preparations of either, in which the dose of opium shall exceed $1 / 4$ grain, or morphine $1 / 20$ grain, except with the verbal or written order of a physician.

It is clearly the duty of the state to close opium dens and restrict the sale of poisons, and in regard to the sale of patent and proprietary medicines containing poisonous drugs, the contents should be expressed on the label and the word poison added.

\section{PATENT AND PROPRIETARY MEDICINES.}

By the term patent medicine, as properly employed in this country, England and Europe generally, it must be understood that the composition is known and can be seen at the patent office. The proprietary medicine is a secret preparation protected by a trade mark in this country, and hence preferred by the owner, but both are vaguely termed by the public patent medicines. Up to I)ec. 10,1900 , the United States patent office had issued patents on the following: $:^{5}$ disinfectants, 321 ; extracts, 250 ; hair dyes and tonics, 48 ; insecticides, 180 ; internal remedies, 376 ; plasters, 56 ; topical remedies, 371 ; veterinary. 78. Trade marks: ${ }^{6}$ drugs and chemicals, 319 ; medical compounds, 5974, and increasing at the rate of about 250 a year.

The proprietary medicines are subject to the control of the state authorities, and if containing alcohol in sufficient quantity to be intoxicants are subject to internal revenue laws; but so far as my knowledge extends, little or nothing has been done in this country and in England to control the sale of secret remedies. Dr. G. Danford Thomas, Coroner of London and Middlesex, before the International Congress of Hygiene, in 1891, very justly urged that all proprietary medicines should be under the patent laws, because the composition is at least disclosed; he would abolish licenses to sell them and confine the sale to chemists and druggists only. In these matters we could certainly profit by the example of the Japanese, Italian. French and German laws. In the interest of public health the profession should demand adequate legislation; as it is now, hundreds of these proprietary preparations, the composition of which need not even be disclosed to the patent office, are advertised in medical journals.

\section{INDUSTRIAL HYGIENE.}

The relations of occupation to health and life were studied as early as 1700 by Ramazzini, an Italian physician, and since then numerous monographs have appeared. We know to-day that persons habitually engaged in hard work, especially in factories and indoors, present a higher mortality than persons more favorably situated, and that the character of occupations influ-

5. Information kindly furnished by Dr. J. B. Littlewood, of the Patent Offee.

6. Information collected from files of the U. S. Patent Office, by the author. 
ences, to a great extent, not only the average expectation of life, but also the prevalence of certain diseases. We know, for example, that tuberculosis is much more frequent among persons engaged in dust-inhaling occupations, and that the sharp angular particles of iron and stone dust are more liable to produce lesions of the respiratory mucosa than coal, flour, grain and tobacco dust. We know, too, that certain establishments, like slaughter-houses, glue, soap and candle factories, chemical factories, etc., are more or less productive of noxious and offensive gases, and that workers in lead, mercury, arsenic: phosphorus, poisonous dyes, etc., suffer especially from the injurious effects, and that other occupations, such as mining, railroading and contact with moving machinery, involve special danger to life and limb.

For all these reasons the laboring classes need special protection, and in order to render this efficient, it must be provided for by the enactment and enforcement of suitable laws. In 1864, 1867 and 1870 England enacted the so-called factory laws. According to Miss S. S. Whittlelsey's "Essay on Massachusetts Labor Legislation," child labor, here as in England, was the first aspect to receive attention in legislation as early as 1836. The first law as regards safety and sanitation was enacted in that state in $187 \%$, since which time, from information kindly furnished by the Hon. Carroll D. Wright, of the U. S. Department of Labor, thirtytwo states have enacted similar laws, including legislation requiring seats to be furnished saleswomen in stores and shops. Indeed, in some of the states the latter requirement is the only sanitary regulation. As a result of these laws, the majority of which were enacted during the last decade, commendable progress has been made in the way of ventilation, heating, lighting, removal of dust and injurious gases, means of escape in case of fire and prevention of injuries by moving machinery.

It is quite true there are other factors which affect the health and longevity of wage-earners adversely. So, for instance, unsanitary dwellings, faulty nutrition-the results of badly prepared food and cold lunches-can not fail to lower the power of resistance to disease, especially when the individual, in consequence of these very causes, has also become a victim of the alcohol habit.

\section{SANITARY DWELLINGS FOR WAGE-EARNERS}

No field affords better opportunity for philanthropic work than the erection of sanitary homes for wageearners at reasonable rentals, the encouragement of cookery schools, the establishment of sanitary lodgings, model eating-houses and other betterments of industrial conditions.

The vital statistics of London show that the mortality in the improved dwellings for wage-earners is far below the general mortality of the city, the difference being specially marked in the infantile mortality; the general average during the five years ending December, 1890 , was 153 per 1000, while in the "George Peabody" and the "Metropolitan dwellings" it was only 136 and 121 respectively. ${ }^{7}$

7. At a recent meeting of the American Social Science Association, held in Washington, April 18, 1901, Mr. J. H. Patterson, Dayton, Ohio, read a paper on factory sanitation and described a large manufacturing plant of which he is the head, and their close adherence to the principles of hygiene and the uplifting of mankind. The interior of the factory is painted in cheerful colors, extra windows were made to give light, forced ventilation to afford plenty of fresh air, and all dust and acid fumes are carried away by exhaust fans. Bath-rooms and well-furnished toilet-rooms are on

\section{RURAL HYGIENE.}

When we consider the fact that over 70 per cent. of our population reside in rural districts, that the "bone and sinew" of these are engaged in agricultural pursuits, and that they do not enjoy the benefits of enforced sanitation by local health boards, we see at once the desirability of the family physician extending useful suggestions on healthful building sites and homes, disposal of house wastes, the importance of a pure water-supply, wholesome and properly cooked food, etc. As it is now, the diet is faulty, especially the hot biscuits, greasy fried dishes, while wells and privies are often dangerous neighbors. The undue prevalence of typhoid fever in rural districts could be materially checked by disinfecting the stools with three times the volume of boiling water and the adoption of the earth closet system. This is all the more important since infection is often spread through the milk-supply, and many of our urban population contract disease in the country during the summer months. While prompt disinfection of the excreta is the only rational method, we should also make an effort to get rid of the flies by prompt disposal of the horse manure in which they breed, the abandonment of open privies and surface pollution, removal of garbage and other fly-breeding matter.

SANITATION OF PRISONS.

Most commendable progress has been made in the construction and management of modern prisons. The mortality at the close of the last century, among prisoners in some of the French prisons, was 250 per 1000 ; between 1840 and 1849 it was still 80.2 per 1000 , at St. Gallen, while to-day it is less than 30 per 1000. Tuberculosis, typhoid fever, diarrhea, croupous pneumonia and mental disorders are the most prevalent diseases, but much will be done in future to reduce the excessive mortality by improved lighting, heating, ventilation, good food, bathing facilities, etc.

In some of the damp, dark and gloomy prisons of Germany over 50 per cent. of all the deaths are from consumption. In the Mill-Bank prison of London, from 1825 to 1842 , were 175 deaths, of which no less than 75 were due to tuberculosis. Besides, 90 prisoners were set free on account of being hopelessly afflicted with pulmonary tuberculosis. In the Illinois State Prison, at Joliet, during the year 1895, 39 deaths were reported from consumption; in 1900 only 8 occurred. 'This decrease appears to be due directly to segregation of tuberculous subjects.

IOSPITALS, SANITARIA AND DISPENSARIES.

Perhaps no country in the world can boast of better hospital facilities than our own. Indeed, many of our institutions are perfect in sanitary architecture and equipment. There are in the United States no less than $17 \% 6$ hospitals, including 35 special hospitals for consump. tives; 308 sanitaria; 213 dispensaries, and over 8000 mineral springs, of which $72 \%$ are health resorts. Un-

all the floors. All seats have backs. Clean aprons are furnished by the company, and a dining-room where hot meals are served and a course in domestic economy is conducted. The grounds around the factory, and the houses of the employees, are healthful and attractive. "We have demonstrated," said Mr. Patterson, "that this system pays the employee, the manufacturer and the buyer in the health of one, profit of the second, and the improved quality of the product purchased by the third." Bulletin No. 31, Department of Labor, November, 1900 , contains an article on betterment of industrial conditions, showing what has elsewhere been accomplished, every effort being in the right direction, exeept that free medical attendance is being furnished by certain companies, involving a contract system with physicians, which ought never to gain a foothold on American soil, because it has proved a bane to the profession elsewhere. 
fortunately the liberality with which medical charities have been supplied has given rise to shameful abuses, and persons who would shrink from seeking charity in any other form have abused the privileges offered by hospitals and dispensaries.

Correction of Abuses.-In 1896, speaking of the city of Washington, no fewer than 21 per cent. of the population received free medical treatment; the medical association in 1897 adopted certain rules compelling the attending staff of hospitals and dispensaries to require evidence of dependency; as a result of this system there has been a gradual but positive decrease in the number of charity patients, amounting to over 9000 last year. It is the simplest, most just and effective remedy for the correction of this evil.

\section{SCHOOL ITYGIENE.}

During the year ending June 30, 1900, there were $15,3+1,220$ children enrolled in the common schools of our country. When we consider that the mental and physical vigor of a nation depends largely on the environments of childhood and youth, it seems strange that up to within forty years little or no attention should have been paid to the hygiene of schools. The occurrence of so-called school diseases is not surprising when we reflect that children, on beginning school, enter upon a new life and environment. Up to this time they have been allowed to run and play in the open air. exercise the body and senses, without restraint, but now without a period of transition they are obliged to remain for several hours a day in close and sometimes unsanitary school rooms, taxing their minds and straining their eyes for near objects. Experience teaches and statistics confirm the conclusion, that quite a number of children suffer from certain physical defects and discases, which because rarely observed before the school period, may be justly attributed to school environments. Among the most common of these affections are myopia, lateral curvature of the spine, dyspepsia, anemia, muscular debility, headache and nose-bleed, nervous affections and tuberculosis. Ware, of our own country, as early as 1812 called attention to the fact that myopia was most frequently developed in the school room, and during the past forty years we have been enlightened as to the cause of this and other defects, and many excellent monographs have been written on the construction of school buildings, arrangement of recitation-rooms; as regards light, ventilation, adjustable seats and desks, proper type for text-books and more rational methods of mental and physical training. This, together with a commendable zeal on the part of the authorities to correct existing evils, has resulted in many reforms, the fruits of which are already apparent in a decrease of the diseases referred to.

Medical Inspection.-I can not enter into details concerning the prevention of the spread of infectious diseases among school children, but desire to emphasize the necessity of medical inspectors, whose duty it should be to visit the schools, examine pupils, and give such directions as will reduce the dangers of spreading contagious diseases to a minimum; they should also make sanitary inspection of the buildings and present such recommendations as are necessary in the interest of the health of both the pupils and teachers, and as the physicians were perhaps the first to recognize the fact that "the system of education should be made to fit the child, not the child the system," the teachers may derive much aid from such consultations; among the cities that have inaugurated such inspections since 1894 , arc Boston.
New York, Brooklyn, Chicago, Milwaukee, Louisville, St. Louis, Philadelphia, Jersey City, Brookline, Mass., Buffalo, Minneapolis and Salt Lake City, and they have proved of inestimable value.

\section{SMLALLPOX AND COMPULSORY VACCINATION.}

In this connection, attention is invited to the undue prevalence of smallpox in the United States; the total number of cases reported to the U. S. Marine-Hospital Service dluring the past fall and winter, up to March 29 , was 11,964 , as compared with 7279 cases for the corrcsponding period of the preceding year, and it is doubtless due to neglect in raceination. Dr. Abbott estimates the vaccinated portion of the inhabitants of the United States at not far from 90 per cent., and the revaccinated portion at probably 50 per cent. With the introduction of glycerinated animal lymph every vestige of prejudice against vaccination should cease, and compulsory laws should be enacted in every state, so that smallpox here, as in the German army, may become practically unknown. While quite a number of states have enacted laws requiring that unvaccinated children shall not be admitted to the public schools, it is believed that these laws are not rigidly enforced.

VENEREAL DISEASES.

A careful perusal of Dr. Prince A. Morrow's article on the "Prophylaxis of Venereal Diseases" (Phila. Med. Jour., April 6, 1901) should stimulate our efforts in the prevention of diseases, which affect not only the offender, but innocent wives, the offspring and not infrequently even the medical attendant. According to Fournier: one-seventh of the population of Paris is syphilitic, and Morrow, from statistics gathered in $\mathrm{New}$ York, believes it is quite possible that Fournier's figures, with some modification, may apply to New York. Neisser holds that gonorrhea is, with the exception of perhaps measles, the most widespread of all diseases. Other German authorities have computed that fully three-quarters of the adult male population and onesixth or more of the adult females have contracted gonorrhea; that 80 per cent. of all deaths from disease of the uterus and its adnexes are of gonorrheal origin. while blenorrhea neonatorum contributes a contingent to our asylums for the blind estimated at from 10 to 20 per cent.--from 40 to 60 per cent. before the Credé method was instituted-not to mention the destructive effects on the procreative functions. Dr. S. M. Burnett. of Gcorgetown University, believes that 15,000 of the 50,000 blind persons in the United States lost their sight from this cause, which according to his calculation involves a financial loss to the commonwealth of seven and one-half millions annually.

The measures which have been proposed for the control of the social evil and the prevention of its consequences are numerous enough, but not so easy of practical application. On the whole I believe the remedy lies in public education, and the task as usual falls on the medical profession, especially the trusted family physician. Public lecturers on the purity of man commit a serious mistake, however, when they picture the consequences of the social evil, without offering a suitable remedy. We should make a strong plea in favor of continence, and tell our young men that while the sexual passion is very strong it can be accelerated or delaved. excited or lowered by the influence of the will. "We should assure them that by the cultivation of pure thought, removal of temptation, normal, mental and rigorous physical exercise, continence may not only 
become possible, but easy. And we can hardly go astray if we follow Dr. Parkes in advising a pure young man to make his home, after the age of 21 , and thus secure himself both from the temptations and expenses of bachelorhood.

\section{THE MANAGEMENT AND CONTROL OF INFECTIOUS}

\section{DISEASES.}

It is the field of infectious diseases where preventive medicine has and doubtless will continue to achieve its greatest triumphs, and there is ample room, when we consider that during the census year of 1890 there were not less than 102.199 deaths from consumption, 74,496 from pneumonia, 74,711 from diarrheal diseases, 41,677 from diphtheria, and 25,058 from typhoid fever. In spite of centuries of groping after facts, we knew nothing of the real nature of infectious diseases until the middle of the present century, and even twenty-five years ago the text-books still discussed the subject of miasma and contagia, whose nature had never been demonstrated to our senses. With improved microscopic lenses and the development of bacteriology, more especially the discovery of the anthrax bacillus by Davaine, Pollender and Brauell (1849-1855), scientific medicine had its birth, and to-day we know that such diseases as tuberculosis, glanders, leprosy, cholera, erysipelas, wound and puerperal infections, gonorrhea, pneumonia, cerebrospinal meningitis, typhoid fever, diphtheria. malaria, influenza, dysentery, bubonic plague, and possibly carcinoma are caused by living organisms, capable of reproduction within and without the body, and this is a strong argument in favor of the microbic nature of wher infecticus diseases, in which the specific organism has not yet been isolated.

The eradication of preventable diseases is the highest aim of scientific medicine to-day. The public should be made familiar with the nature and causes of infectious discases, and be taught that many are a source of danger, against which it is entitled to be warned by proper notification through the health officer. This notification should be made compulsory in cholera, yellow fever, smallpox, chicken-pox, typhus and typhoid fever, diphtheria and membranous croup, scarlet fever, tuberculosis, cerebrospinal meningitis, leprosy, glanders, bubonic plague, whooping-cough and measles. And let me say that a prompt and correct diagnosis is the first and most important step in preventive measures. The health department should have competent medical inspectors and a clinical laboratory for the verification of the diagnosis, and have the power in certain of these diseases to display warning signs, enforce isolation and disinfection, and to take such other steps in the way of immunizing agents as may be deemed necessary to limit their spread.

Isolation, to be effective, should extend to all persons who have come in intimate contact with the patient, but this is rarely enforced except in smallpox, in the case of the attending physician, and the wage-earners of the family, but it is clearly their duty to take special precautions in the way of clothing and personal disinfection. Matters of this kind ought never to be left to the discretion of the family, nor the attending physicians, for even members of the profession often entertain widely opposing opinions on the subject of quarantine and disinfection, but the principles which ought to be carried out, apart from being a matter of conscience, should be accepted in a practical sense and embodied in effective laws.

Disinfection.-Scientific disinfection had its inception with the labors of Koch and Sternberg some twenty years ago. Although, as we have seen, certain physical and chemical agents were used empirically for ages, now we know from laboratory experiments that they are effective, because they destroy the vitality of the germs. We also know that, in most of the contagious diseases, the infective matter is given off by the patient chiefly through the secretions and excretions, and it.is evident that disinfection to be of value must be directed to these and all the media with which the patient has come in contact.

\section{"IF CERTAIN DISEASES ARE PREVENTABLE, WHY ARE THEY NOT PREVENTED?"}

My answer is, that while every scientific physician familiar with biologic research knows full well that if the methods of prevention recommended by sanitarians, including the prompt disinfection of the dejecta of every typhoid fever patient, the expectoration and excretions of diphtheria and tuberculosis patients, for example, were adopted, these diseases would be reduced to a minimum and probably eradicated in the course of a few years. The facts are, these recommendations have not been generally adopted, because the knowledge gained by experimental medicine is not sufficiently diffused. Nor are we responsible for the fact that so many of our states still permit every charlatan to practice one of the most difficult and responsible of all professions without a uniform and rigid system of examination. However, we owe it to ourselves and to humanity to take positive steps in behalf of higher medical education and laws regulating the practice of medicine. So long as we permit the existence of irregular and incompetent practitioners, so long will the public be deceived. and so long as we tolerate the exponents of so-called "Christian Science," osteopathy, and other quacks, infectious diseases will be spread as the result of ignorance and neglect. A strong organization, such as is proposed for the AMERICAN MEDICAL Association and the various state medical societies will speedily accomplish this and other reforms.

[During the year 1900 there were 119 regular medical schools in this country, with 1079 female and 21,673 male students; of these 22,752 students, 2327 , or about 10 per cent., had de grees of A.B. or B.L. Number of graduates last year, 4720 'The homeopathic schools had 1534 male and 325 female students, and the eclectics 500 male and 52 female students. The number of registered physicians in the United States in 1900 shows an average for the whole of about 1 to 636 inhabitants. In 31 states and territorics, according to D. McIntyre, an examination is required, in 9 certain diplomas are accepted, all others must be examined; in 5 only a diploma is required, and in 5 the laws practically impose no restriction. In 1900 there were 150 national and state medical societies, 1097 county and local medical societies, and 282 medical journals, of which 28 were exchusively devoted to hygiene and public health.]

FORECAST OF THE RESULT OF THE CENSUS WORK UPON THE MORTALITY STATISTICS.

Notwithstanding these and other disadvantages in the way of defective sanitary legislation, the American medical profession has reason to be proud of its work in the century's progress of hygiene and preventive medicine. It may be truly said that every hospital or other medical charity owes its foundation and success to the activities of the medical profession. Nay, every law inscribed on the statute books, in the interest of public health in this and other countries is the work of our noble profession. Acting upon the lofty principle that the education and betterment of the people in sanitation is not less humane than the healing of the 
sick, the American medical profession has filled the measures of its philanthrophy by advocating laws to "regulate the health and physical well-being of communities," and thereby lessen its own income, but the results obtained during the last ten years are sufficient recompense. By the courtesy of Mr. Wm. A. King, Chief Statiscian of the U. S. Census Bureau, I am enabled to give you a forecast of the result of the work upon the mortality statistics at the close of the century:

The mortality returns for the twelfth census, which relate to the year beginning June 1, 1899, and ending May 31,1900 , have not yet been tabulated in full, but sufficient progress has been made to permit a comparison of the preliminary results with the figures for 1890 for a portion of the country.

Considering these results for these states in which the returns were secured from registration records in both 1890 and 1900, there appears to have been an absolute decrease in the general death-rate of about 1.5 per 1000 of population. This decrease seems to be most marked in the rates due to scarlet fever, whoopingcough, diphtheria and croup (combined), typhoid fever, malarial fever, consumption, diarrheal diseases, and diseases of the nervous system, the decrease in the mortality from diphtheria and croup amounting to more than 50 per cent. On the other hand, the rates due to carcinoma and tumor (combined), Bright's disease, heart disease and dropsy (combined), and pneumonia are apparently greater than in 1890 , the increase being most marked in case of Bright's disease, carcinoma and tumor, and pneumonia.

The death-rate by age periods in the registration states has not yet been computed as the population figures are not yet available, but the effect of the decrease in the rates due to the causes specified is shown by a decrease in the proportion of deaths occurring at each period up to 30 years.

The results in the decreased rate of diphtheria, croup, scarlet fever, typhoid fever, whooping-cough, consumption, malarial fever and diarrheal diseases are the direct outcome of preventive medicine and are as gratifying as they are striking. We note with regret the increased rate in Bright's disease, heart disease, dropsy and pneumonia, and may well pause to inquire whether our everincreasing "National Drink Bill," averaging" 17.68 gallows per capita, may not be a factor in the developm nt of these diseases, especially since there is reasou to bclieve that the habitual and immoderate use of alcohol, apart from increasing the connective tissue and causing cirrhosis, also produces fatty degeneration, especially of the heart, liver and arterial coats, probably because it promotes the conversion of albuminoids into fats.

Without wishing to under-rate the brilliant achievements in surgery of the brain, stomach, intestines, liver, gall-bladder and other abdominal organs, and even wounds of the human heart which have been successfully sutured in four of the nine cases reported, what after all are the ultimate benefits compared with the results obtained by improved methods in sanitation?

Since our knowledge of the nature of infectious diseases has been more and more defined, scientific methods for their prevention have been applied. We have learned, too, that in addition to the germ there must be a suitable soil for its proliferation and that sanitation will not only destroy the environments for its development without the body, but also place the system in the best possible condition to resist its toxic action.

The application of this knowledge has saved millions of lives besides an incalculable amount of human suffering and distress, not to mention the economic aspect of the question. When we remember all this and the fact that Jenner's discovery at the close of the last century, of a fundamental and practical method of producing artificial immunity, has been far eclipsed in the last twenty years, and that we possess to-day not only curative but also protective sera for diphtheria, erysipelas, tetanus, plague and possibly cholera, tubereulosis, typhoid fever, pneumonia, and a number of other immunizing agents for diseases of man and lower animals, we have reason to believe that the solution of the problem of immunity is only a question of time, and we may indeed expect great possibilities in our battle against infectious diseases.

To the solution of this problem, the labors of Salmon and Smith, Sternberg, Welch, Osler, Councilman, Reed and other Americans engaged in experimental medicine have contributed their full share. Progress has crowned our past, we will not retrograde. Let our conduct raise no blush on the cheek of posterity. Let us hand in hand with heart and mind join in promoting the welfare of American medicine, until she has reached the proudest pinnacle in the world of science, until she has become the fountain-head of knowledge for the benefit of mankind. Then when at last we are called upon to pass through the portals beyond, Minerva Medica, in her sweeping robes of state, will proudly but reverently present us to the Supreme Healer of the Universe as types of the true physician. ${ }^{8}$

Symptoms of an Affection of the Pancreas.-Scherschewski calls attention to the fact that the pancreas lies directly above the aorta and its plexus and receives its bloodsupply from the same vessels as the liver and spleen. $I t$ is therefore probable that an affection of the spleen is usually complicated by a sympathetic lesion in the pancreas. Slight enlargement of the pancreas compresses the aortic plexus but as the enlargement progresses, the lumen of the aorta is also compressed and below this point the aortic sound is transformed into a murmur. A constant murmur, therefore. in the aorta indicates enlargement of the pancreas. Changes in the size of the spleen in the course of a few days, suggest an affection of the pancreas in the absence of malaria. Compression of the aortic plexus causes girdle pains and typical pains in the bladder and ureter. They are inconstant, resemble gallstone colic, are more or less periodical, appear soon after eating and last one or two hours. They frequently appear at 1 to 2 a. $m$. They are not severe but are accompanied by intense nausfa and weakness. They are never accompanied by defecation and have no connection with the amount or quality of the food. Another symptom is a pulsation in the stomach region, with cardiac distress and palpitations, independent of the condition of the stomach or ingestion of food. In most of his fourteen eases there was a history of malaria six or seven years previously. Malarial cachexia is probably due to an affection of the pancreas in many cases. In four patients the influence of a trauma was evident. He administered pancreatin in doses of $.3 \mathrm{gm}$. after meals, with or without .01 ext. belladonnæ, with plastic clay on the stonach region, sometimes alternating with ice. Devoto has recently announced that any factors, traumatic or otherwise, which diminish the resistance of the organ or allow the penetration of the bacterium coli into the pancreatic duct, favor the evolution of acute pancreatitis. It may be accompanied by effusion, hemorrhagic or not, or by suppuration. 8. In the preparation of this address, I have been greatly aided
by the Library of the Surgeon-General's Office, the historical monoby the Library of the Surgeon-General's Office, the historical mono-
graphs on hygiene, by Professor Finkellnburg, of Bonn, now degraphs on hygiene, by Professor Finkellnburg, of Bonn, now detion, and Dr. A. E. Miller of his Bureau. Other acknowledgments tion, and Dr. A. E. Miller of his Bureau. Other ackn
have been made in the text and are gratefully renewed. 